\title{
Sociodemographic and Nutritional Factors Associated with Adherence to Antiretroviral Therapy in PLWHA in Benin
}

\author{
Charles Sossa Jérome ${ }^{1,2, *}$, Maurice Togbédji Agonnoudé ${ }^{1,3}$, Moussiliou Noel Paraiso², \\ Ali Imorou Bah-Chabi ${ }^{1}$, Amédée de Souza ${ }^{1}$, Moussa Bachabi ${ }^{1}$, Gratien Gbetowenonmon ${ }^{1}$, Victoire Agueh ${ }^{2}$ \\ ${ }^{1}$ National Aids Control Programme (PNLS), Benin \\ ${ }^{2}$ Regional Institute of Public Health, University of Abomey-Calavi, Benin \\ ${ }^{3}$ National High School of Epidemiological Surveillance (ENATSE), University of Parakou, Benin
}

Copyright $\bigcirc 2017$ by authors, all rights reserved. Authors agree that this article remains permanently open access under the terms of the Creative Commons Attribution License 4.0 International License

\begin{abstract}
Adherence to antiretroviral treatment (ART) is critical for suppression of viral replication, repletion of $\mathrm{CD}_{4}$ cells, avoiding viral resistance, improving immune response and slowing HIV infection progression. This study sought to measure adherence to ART and to determine its associated sociodemographic, lifestyle and nutritional factors in HIV-infected adults taking antiretroviral (ARV). Using a cross-sectional study design, medical records of 991 HIV positive patients who started antiretroviral therapy from July, $1^{\text {st }} 2011$ to June, $30^{\text {th }} 2012$ were reviewed. Data were collected in 2014 in $46 \mathrm{HIV} /$ AIDS therapy centers across Benin, The independent variables were sociodemographic, lifestyle, nutritional and therapeutic factors. The main dependent variable was the adherence to the ART. Chi-square test was used to determine the association between dependent and independent variables. A p-value < 0.05 was considered statistically significant. Out of 991 PWLHIV, 30.2\% showed poor adherence to ARV. Factors associated with ART adherence were social network $(p<0.001)$, gender $(p=0.020)$ and nutritional status based on body mass index $(\mathrm{p}=0.006)$. The prevalence of non-adherence to ART was high in PLWHA taking ARV. Efforts are needed to improve adherence to antiretroviral therapy in PLWHA in Benin. Intensive adherence counseling should be provided to all patients before initiation of antiretroviral therapy. Health care providers must contribute to social networking in patients and ensuring nutritional support to them.
\end{abstract}

Keywords ARV Therapy, Benin, PWLHA, Therapeutic Adherence

\section{Introduction}

Acquired immune deficiency syndrome (AIDS) is now a manageable chronic illness. To achieve expected maximal results from antiretroviral therapy (ART), patient adherence to ART is critical [1]. The benefits of highly active antiretroviral therapy in the treatment of HIV infection have been well described including viral suppression, CD4 lymphocyte repletion, and reductions in AIDS related opportunistic diseases and death [2]. According to literature review, main factors that affects adherence to ART were social capital [3], stigmatization and discrimination [4;5], barriers to accessibility to care (distantly health care facilities, costs of care, travel costs) [6], depression condition [7], educational level [8], overburden work load [7]. Factors that limit the success of ART include poor therapy adherence, regimen complexity, viral resistance, drug tolerability and toxicity, therapy costs, and presence of comorbid conditions such as substance abuse and addiction [1].

In Benin, ART began since February 2002 in three sites. In scaling up according to 3 by 5 initiative, Benin national AIDS control program (PNLS) opted for decentralized health centers for HIV/AIDS care [9]. In 2014, 1718, people living with HIV/AIDS (PLWHA) with highly active ART (HART) (6.3\%) aged 15 years and over were reported drop out in 2014. Poor adherence severely impacted negatively on effectiveness of HART and was linked with the likelihood of the drug resistance [10]. To improve program performance and quality of services to PLWHA, we need to understand, in view of actual implementing experiences, the factors that influence patient adherence to ART. 


\section{Material and Methods}

\subsection{Setting}

Patients were selected in 46 HIV/AIDS care sites in all parts of Benin.

\subsection{Study Design and Population}

The study was a cross-sectional one. The study population was PLWHA who started ART from July, $1^{\text {st }} 2011$ to June, $30^{\text {th }}$ 2012. The present study is part of the study on PLWHA's one year survival.

\subsection{Selection of ART Centers and Participants}

Forty two (42) ART centers with active queue of more than 100 patients were randomly selected out of all 86 centers available in Benin in 2014. In order to take into account representativeness of sites, four complementary sites with fewer than 100 patients, were randomly selected. PLWHA whose medical records included complete information on adherence to ART participated in the study.

Inclusion criteria were: being HIV positive, start antiretroviral therapy from July, 1st 2011 to June, 30th 2012. Exclusion criterion was being pregnant woman taking ART for preventing mother to child HIV infection.

\subsection{Study Variables}

The independent variables were sociodemographic, lifestyles and nutritional factors. The main dependent variable was the adherence to ART. Adherence is defined as a patient's ability to follow a treatment plan, take medications at prescribed concerning times and frequencies. Adherence measurement in this study was based on the number of missed medication. Good adherence referred to compliance with medical recommendations with optimal regularity $(\leq 1$ missed medication in a month). Poor adherence meant patient not consistent with medical recommendations $(>1$ missed medication in a month). Patients whose medical reports pointed out one or more missed doses (forgetting of skipping medication) within a month were considered showing poor adherence [11].

\subsection{Data Collection}

Data were collected from patient medical record and regular patients' data base in each site. Investigators were divided in duo: each had to cover one or many HIV/AIDS care sites according to patients' active file in the site and distance between sites. Investigators were enrolled for two days training to be familiar with study procedure. National supervision of data collection was also set.

\subsection{Statistical Analysis}

Data are collected from regular patients' medical records in each site and were analyzed using SPSS version 20.0. Chi square test was used to determine the association between dependent and independent variables

\subsection{Regulatory Approvals}

The study was approved by Benin National Health Research Ethics Committee before the operational stage beginning. The interviewer explained the purpose of the study and procedures and gained written informed consent before commencing the interview. The participants were also informed that their participation was voluntary and that they could withdraw from the interview/discussion at any time without consequences. The participants were assured that their responses would be treated in confidence and they were assured anonymity through the use of strict coding measures.

\section{Results}

A total 991 patient's medical records out of 3295 eligible had complete data regarding main dependent and independent variables.

\subsection{Scio-demographic Characteristics}

Table 1 summarizes socio-demographic characteristics of participants. The majority of the patients were female $(69.6 \%)$ and $59.9 \%$ aged between 30 and 49 years. The mean age of participants was $36.4 \pm 10.6$ years. Most patients (66.4\%) were married, $48.2 \%$ were with illiteracy and $28.0 \%$ were housewives. Participants were less involved in social network as $89.0 \%$ of them were not member of any association and $242 \%$ were living with their partner and infants.

\subsection{Health Risk Behaviour Characteristics}

Table 1 shows lifestyles and health risk factors in PLWHA in HART including currently smoking and drinking alcohol. Most of participants didn't smoke (98.2\%) while almost 10\% consumed alcohol and $23.8 \%$ were underweight (Body mass index $<18.5)$. Table 2 shows that participants in stage 2 and 3 of WHO AIDS classification represented $26.8 \%$ and $46.6 \%$ respectively and $99.4 \%$ of participants were taking first line ART.

\subsection{Medical History and ART Treatment}

The mean duration of receiving ART was $14.4 \pm 7.6$ months. The number of patients who reported being admitted in hospital after being infected with HIV during last 12 months due to poor health or opportunistic infection was $8 \%$. The most common reasons for hospital admission were prolonged fever and chronic diarrhea. 
Sociodemographic and Nutritional Factors Associated with Adherence to Antiretroviral Therapy in PLWHA in Benin

Table 1. Factors associated with adherence to ART in PLWHA taking antiretroviral ( $n=991)$, Benin 2014

\begin{tabular}{|c|c|c|c|}
\hline Characteristics & Poor adherence & Adequate adherence & $\mathrm{p}$ \\
\hline \multicolumn{4}{|l|}{ Sex } \\
\hline Women & 690 & 69.6 & \multirow{2}{*}{0.020} \\
\hline Men & 301 & 30.4 & \\
\hline \multicolumn{4}{|l|}{ Age } \\
\hline $16-29$ & 276 & 27.8 & \multirow{3}{*}{0.909} \\
\hline $30-49$ & 594 & 59.9 & \\
\hline 50 and above & 121 & 12.2 & \\
\hline \multicolumn{4}{|l|}{ Education } \\
\hline Illiterate & 478 & 48.2 & \multirow{4}{*}{0.355} \\
\hline Writing in locale language & 21 & 2.1 & \\
\hline Primary school & 274 & 27.6 & \\
\hline Secondary school & 198 & 20.0 & \\
\hline \multicolumn{4}{|l|}{ Occupation } \\
\hline Housewife & 277 & 28.0 & \multirow{7}{*}{0.592} \\
\hline Student & 35 & 3.5 & \\
\hline Farmers & 78 & 7.9 & \\
\hline Craftsmen, artists and traders & 321 & 32.4 & \\
\hline Private staff/ Self employed & 55 & 5.5 & \\
\hline Government staff & 67 & 6.8 & \\
\hline Others & 158 & 15.9 & \\
\hline \multicolumn{4}{|l|}{ Marital status } \\
\hline Single & 128 & 12.9 & \multirow{4}{*}{0.932} \\
\hline Married & 658 & 66.4 & \\
\hline Widowed & 115 & 11.6 & \\
\hline Others & 90 & 9.0 & \\
\hline \multicolumn{4}{|l|}{ Family network } \\
\hline Alone & 100 & 10.1 & \multirow{6}{*}{0.507} \\
\hline Living with a partner & 259 & 26.1 & \\
\hline Living with infants & 145 & 14.6 & \\
\hline Living with partner and infants & 416 & 42.0 & \\
\hline Living in extended family & 61 & 6.2 & \\
\hline Others & 10 & 1.0 & \\
\hline \multicolumn{4}{|l|}{ Social network } \\
\hline Not a member an association & 882 & 89.0 & \multirow{3}{*}{$<0.001$} \\
\hline Active member of an association & 81 & 8.2 & \\
\hline Passive member of an association & 28 & 2.8 & \\
\hline \multicolumn{4}{|l|}{ Smoking } \\
\hline Yes & 18 & 1.8 & \multirow{2}{*}{0.325} \\
\hline No & 973 & 98.2 & \\
\hline \multicolumn{4}{|l|}{ Alcohol consumption } \\
\hline Yes & 97 & 9.8 & \multirow{2}{*}{0.434} \\
\hline No & 894 & 90.2 & \\
\hline \multicolumn{4}{|l|}{ Body mass index } \\
\hline$<18.5$ & 198 & 23.8 & \multirow{3}{*}{0.010} \\
\hline $18.5-24.9$ & 334 & 40.1 & \\
\hline 25 and above & 301 & 36.1 & \\
\hline
\end{tabular}

$\mathrm{p}$ : $\mathrm{p}$ for Chi-square 
Table 2. WHO HIV infection staging and antiretroviral treatment in PLWHA PLWHA ( $\mathrm{n}=991)$, Benin 2014

\begin{tabular}{|c|c|c|}
\hline Characteristics & $\begin{array}{c}\text { Absolute } \\
\text { frequency }\end{array}$ & $\begin{array}{c}\text { Relative } \\
\text { frequency(\%) }\end{array}$ \\
\hline Antiretroviral combination used & & 99.4 \\
\hline First line antiretroviral therapy & 985 & 0.6 \\
\hline Second line Antiretroviral therapy & 6 & 19.6 \\
\hline WHO HIV infection staging & & 26.8 \\
\hline Stage 1 & 160 & 46.6 \\
\hline Stage 2 & 219 & 7.1 \\
\hline Stage 3 & 381 & \\
\hline Stage 4 & 58 & \\
\hline
\end{tabular}

\section{Discussion}

This study focused on determining the relation of sociodemographic, lifestyle and nutritional factors with adherence to ART among adult people living with HIV taking antiretroviral therapy in Benin. Based on the review of patients' medical records, results indicated that almost one third of the PLWHA showed poor adherence to ART. Adherence to ART in this study was associated with sex, social networking and nutritional status.

\subsection{Prevalence of Adherence to ART}

The result of $69.2 \%$ ART adherence among PLWHA in the study is in convergence to those found in India and in Zambia $[12 ; 13]$, but lower than finding reported in China [14], and Vietnam [15]. Proportion of adherence to ART is also lower than those reported in developed countries $[1 ; 16]$. Some caution is needed in comparing adherence rates across studies since the methods of measuring adherence (medical records review, pill counts and blood analysis) can affect findings. Assessing ART adherence is difficult as patients may over or underestimate their adherence due to recall bias and the desire to avoid criticism [16].

\subsection{Factors Associated with Adherence to ART}

In the study, proportion of non-adherent in women was lower than proportion of non- adherent in men. In contrast, a study among Canadian cohort of HIV-positive, authors reported that female gender was independently associated with a lower likelihood of being adherent to $\mathrm{ART}(\mathrm{OR}=0.70$; $95 \% \mathrm{Cl}: 0.53-0.93)$, after adjusting for clinical characteristics as well as drug use patterns measured longitudinally throughout follow-up [17].

In a gender-stratified multivariate analysis study in Montefiore Medical Center's Substance Abuse Treatment Program in the Bronx, New York, authors reported that gender difference in adherence to ART was explained by others factors. Worse adherence in women was associated with problem of alcohol use and active heroin use. In contrast, for men, not belonging to an HIV support group and active crack or cocaine use were associated with worse adherence [18].

In the present study, proportions of being member of an association were not significantly different between men and women. In contrast BMI status distribution differed significantly between men and women $(p<0.001)$. This could partly explain gender difference in adherence to ART.

Being active member of an association was associated to adherence to ART. Social capital effect on therapeutic adherence has been shown by others [3]. In three countries (Nigeria, Uganda, Tanzania), social capital (link with neighbour and carers) and patients social responsibility or accomplishment lead the latter to adequate adherence of ART [3]. In our study, a survey with ARV site leaders has shown that near third $(28.6 \%)$ of them hasn't take any action of networking PLWHA, nor organizing adherence training for patients, family or community.

In the study, no effect of educational level on adherence was pointed out. In literature, educational level effect on therapeutic adherence was controversial. Hansana et al. [8] reported positive effect of the first on the latter while Getachew et al. [19] have shown that educational status of PLWHA taking ARV was negatively associated with adherence to ART.

Malnutrition which referred to $\mathrm{BMI}<18.5 \mathrm{Kg} / \mathrm{m}^{2}$ in the study was significantly associated with non-adherence to ART. Malnutrition was more frequent in the non-adherent (38\%) participants than in the adherent $(28 \%)$ counterparts. This is in line with a quasi-experimental study in Zambia [20], in Uganda [21] which reported that better nutritional status improves adherence to ART. However, this is not in line with the cross sectional study in Ethiopia which reported that nutritional status showed no impact on adherence to ART [22]. This study reported that people with good nutritional status miss ARV doses more than those with poor nutritional status [22]. Difference in studies design may explain these results.

AIDS control programs managers and heath careers can design and implement a set of feasible interventions basing on findings to maximize adherence. Indeed, according to World Health Organization, [23], some feasible interventions have proven their efficacy on therapeutic 
adherence: networking PLWHA with voluntary or community workers, pairs support and adherence support groups, ensuring nutritional support to PLWHA taking antiretroviral therapy. At individual level, feasible interventions are SMS reminders, nutritional support, and adherence training for patients, their families and the whole community.

The study has some limitations. It hasn't examined the social representations that patients receive from antiretroviral treatment that can affect adherence to therapy. Also, the study didn't examine ARV stocks shortage and the quality of the relation between health workers and patient which were not included in the present study's objectives.

\section{Conclusions}

Adherence to antiretroviral therapy in Benin was suboptimal. Sociodemographic and nutritional factors were associated to adherence to ART. Intensive adherence counseling should be provided to all patients before initiation and during antiretroviral therapy. Health care providers should base their intervention on associated factors identified in the study.

\section{Conflict of Interest}

Authors declare no conflict of interest.

\section{Acknowledgements}

We thank Global Fund for Malaria, HIV/AIDS and tuberculosis Representative in Benin and its partner PNLS for funding this study as periodic evaluation of ART care for PLWHA. We thank also all ARV cares sites managers and PLWHA cares centers (CIPEC) managers for their contributions to data collection in this study.

\section{Authors' Contribution}

SJC and MTA wrote the proposal and supervised data collection. SJC, MNP and MTA did the analysis and wrote the draft of the report. All authors contributed to final version of the manuscript.

\section{REFERENCES}

[1] Nieuwkerk PT, Sprangers MA, Burger DM, Hoetelmans RM, Hugen PW, Danner SA (2001). Limited patients' adherence to highly active antiretroviral therapy for HIV-1 infection in an observational cohort study. Arch Intern Med., 161: 1962-1968. 10.1001/archinte.161.16.1962.
[2] Abaasa AM, Todd, Kenneth JE, Kalyango, JN, Levin J, Odeke E, Karamagi, C.AS. . (2008). Good adherence to HAART and improved survival in a community HIV/AIDS treatment and care programme: the experience of The AIDS Support Organization (TASO), Kampala, Uganda. BMC Health Services Research, 8, 214-250. doi: 10.1186/1472-6963-8-241

[3] Ware NC, Idoko J, Kaaya, S, Biraro, I.A., Wyatt, MA, Agbaji, O. Bangsberg, David R. . (2009). Explaining adherence success in sub-Saharan Africa: An ethnographic study. PLoS Med, 6(1), 39-47. doi: 10.1371/journal. pmed.1000011

[4] Kang'ethe, M S, Nomngcoyiya T. (2015). Exploring Underpinnings Weighing Down the Phenomenon of Adherence to Anti-Retroviral Drugs (ARVs) among the People Living With HIV/AIDS(PLWHA) in South Africa and Botswana: A Literature Review. Journal of Human Ecology 50(3), 237-243.

[5] Vu Van T, Pharris, Thorson A, Alfven AT, Larsson M (2011). "It is not that I forget, it's just that I don't want other people to know": barriers to and strategies for adherence to antiretroviral therapy among HIV patients in Northern Vietnam. AIDS Care: Psychological and Socio-medical Aspects of AIDS/HIV, 23(2), 139-145. doi: 10.1080/09540121.2010.507741

[6] Portelli, M.S., Tenni B, Kounnavong S, Chanthivilay P (2012). Barriers to and Facilitators of Adherence to Antiretroviral Therapy Among People Living With HIV in Lao PDR: A Qualitative Study. Asia Pacific Journal of Public Health. doi: 10.1177/1010539512442082

[7] Oku, Afiong O, Owoaje, T Eme, Ige, Olusimbo, K, \& Oyo-ita, Angela (2013). Prevalence and determinants of adherence to HAART amongst PLHIV in a tertiary health facility in south-south Nigeria BMC Infectious Diseases, 13, 401-409.

[8] Hansana, Visanou, Sanchaisuriya, Pattara, Durham, Jo, Sychareun, Vanphanom, Chaleunvong, Kongmany, Boonyaleepun, Suwanna, \& Schelp, Frank Peter. (2013). Adherence to Antiretroviral Therapy (ART) among People Living With HIV (PLHIV): a cross-sectional survey to measure in Lao PDR BMC Public Health 13, 617.

[9] Programme National de Lutte contre le Sida (PNLS). (2014). Rapport du monitoring du deuxieme semestre 2014. Cotonou: PNLS, Ministère de la Santé du Bénin.

[10] Ferrand, A. Rashida, Briggs, Datonye, Ferguson, Jane, Penazzato, Martina, Armstrong, Alice, MacPherson, Peter, . . . Kranzer, Katharina. (2015). Viral suppression in adolescents on antiretroviral treatment: review of the literature and critical appraisal of methodological challenges. Tropical Medicine and International Health, 0(0). doi: 10.1111/tmi.12656

[11] Sahay S, Reddy KS, Dhayarkar S. (2011). Optimizing adherence to antiretroviral therapy. Indian J Med Res; $134: 835-49$

[12] Birbeck GL, Chomba E, Kvalsund M, Bradbury R, Masng'ombe C, Malama K (2009). Antiretroviral Adherence in rural Zambia: The First Year of Treatment Availability. AmJTrop Med Hyg, 80 (4): 669-674.

[13] Wang XQ, Wu ZY (2007). Factors associated with adherence to antiretroviral therapy among HIV/AIDS patients in rural China. AIDS, 21 (8): 149-155 
[14] Tran BX, Houston S (2012). Mobile Phone-Based Antiretroviral Adherence Support in. 2012, Feasibility, Patient's Preference, and Willingness-to-pay. AIDS Behav: Vietnam

[15] Chesney MA (2006). The Elusive Gold Standard: Future Perspectives for HIV Adherence Assessment and Intervention. Jaids J Acquir Immune Defic Syndr, 43 (1): 149-155.

[16] Kumarasamy N, Safren SA, Raminani SR, Pickard R, James R, Krishnan AKS (2005). Barriers and facilitators to antiretroviral medication adherence among patients with HIV in Chennai, India: a qualitative study. AIDS Patient Care STDS. 9 (8): 526-37.

[17] Tapp C. Milloy M-J, Kerr T., Zhang R, Guillemi S., Hogg RS, Montaner J. Wood E. (2011). Female gender predicts lower access and adherence to antiretroviral therapy in a setting of free healthcare. BMC Infectious Diseases 201111:86. DOI: 10.1186/1471-2334-11-86

[18] Berg KM, Demas PA, Howard AA, Schoenbaum EE, Gourevitch MN, Arnsten JH (2004). Gender Differences in Factors Associated with Adherence to Antiretroviral Therapy. J Gen Intern Med. 19(11): 1111-1117. doi: 10.1111/j.1525-1497.2004.30445.

[19] Getachew A, Gizachew TA, Hiwot K. (2014). Adherence to antiretroviral therapy and its associated factors among children at South Wollo Zone Hospitals, Northeast Ethiopia: a cross-sectional study. BMC Public Health, 14(365). doi: 10.1186/1471-2458-14-365

[20] Cantrell RA, Sinkala M, Megazinni K, Lawson-Marriott S, Washington S, Chi BH (2008). A Pilot Study of Food Supplementation to Improve Adherence to Antiretroviral Therapy among Food-Insecure Adults in Lusaka, Zambia. JAIDS J Acquir Immune Defic Syndr; 49(2):190-195. doi: 10.1097/QAI.0b013e31818455d2.

[21] Rawat R, Kadiyala S, McNamara PE. The impact of food assistance on weight gain and disease progression among $\mathrm{HIV}$-infected individuals accessing AIDS care and treatment services in Uganda. BMC Publ Health. 2010; 10: 316. doi: 10.1186/1471-2458-10-316.

[22] Abiy S. Impact of Food and Nutrition Security on Adherence to Anti-Retroviral Therapy (ART) and Treatment Outcomes among Adult PLWHA in Dire Dawa Provisional Administration. Addis Ababa University [Internet] 2007. Available from: http://hdl.handle.net/123456789/861.

[23] World Health Organization. (2013). Consolidated guidelines on general HIV care and the use of antiretroviral drugs for treating and preventing HIV infection: recommendations for a public health approach. (D. o. HIV/AIDS, Trans.) Guidelines. Geneva: World Health Organization. 